\title{
TANTANGAN INDUSTRI COLD SUPPLY CHAIN PRODUK MAKANAN BEKU
}

\author{
Yuli Evitha \\ Program Studi Manajemen Logistik \\ Fakultas Ilmu Sosial dan Manajemen \\ Institut Ilmu Sosial dan Manajemen STIAMI \\ Email : evitha@stiami.ac.id
}

\section{ARTICLE INFO}

Keywords:

cold supply chain, frozen

food

\section{ABSTRACT}

The purpose of this paper is to analyze the challenges faced by the cold supply chain industry in Indonesia, especially for frozen food products. The challenges faced are temperature control in storage and distribution and the food distribution speed. This is due to inadequate infrastructure conditions in Indonesia. It is suggested that the government should build and improve infrastructure and provide incentives such as tax incentives, given that the cold supply chain industry is very expensive.

\section{PENDAHULUAN}

Industri bahan makanan beku merupakan salah satu industry yang kian berkembang di Indonesia karena makanan beku dianggap sebagai salah satu bentuk gaya hidup yang tidak bisa dihindari. Makanan beku tersebut bisa berupa bahan makanan yang mentah alias belum diolah seperti daging beku, ikan beku, ayam beku maupun makanan yang telah diolah sebelumnya seperti nugget, sosis dan sebagainya.

Industri makanan beku tidak lepas dari peran rantai pasok yang cukup rumit pelaksanaannya, Rantai pasok ini mengharuskan mendistribusian makanan beku harus selalu dalam keadaan dingin sehingga bahan makanan beku tersebut tidak rusak. Kegiatan rantai pasok ini lebih dikenal dengan sebutan Cold Supply Chain atau rantai pasok dingin.

Dalam hasil wawancara dengan salah satu narasumber,yang merupakan pelaku industri cold supply chain, mengatakan bahwa industri cold supply chain adalah industry rantai pasok dengan resiko yang sangat besar. Dikatakan bahwa keuntungan dari tiap pendistribusian hanya sekitar 10 juta rupiah dibandingkan dengan resiko apabila terdapat kesalahan dalam pendistribusian misalnya makanan rusak maka perusahaan harus mengganti biaya kerugian sebesar 150 juta rupiah. Selain itu, dalam cold supply chain juga membutuhkan biaya yang relatif tinggi. Biaya ini digunakan untuk pembelian dan pemeliharaan kendaraan dan peralatan yang relative mahal serta biaya operasionalnya yang relative lebih mahal dibanding rantai pasok lainnya.

Meski pengelolaan cold chain memakan proses yang rumit serta biaya yang cukup tinggi, namun industry cold chain memiliki potensi yang sangat besar untuk jauh lebih berkembang. Hal ini tergambar dalam grafik di 
bawah ini yang mengungkapkan bahwa masih ada gap yang sangat tinggi antara kebutuhan dan kapasitas penyedia jasa cold supply chain.

Sumber: Kementrian Kelautan dan Perikanan (2016)

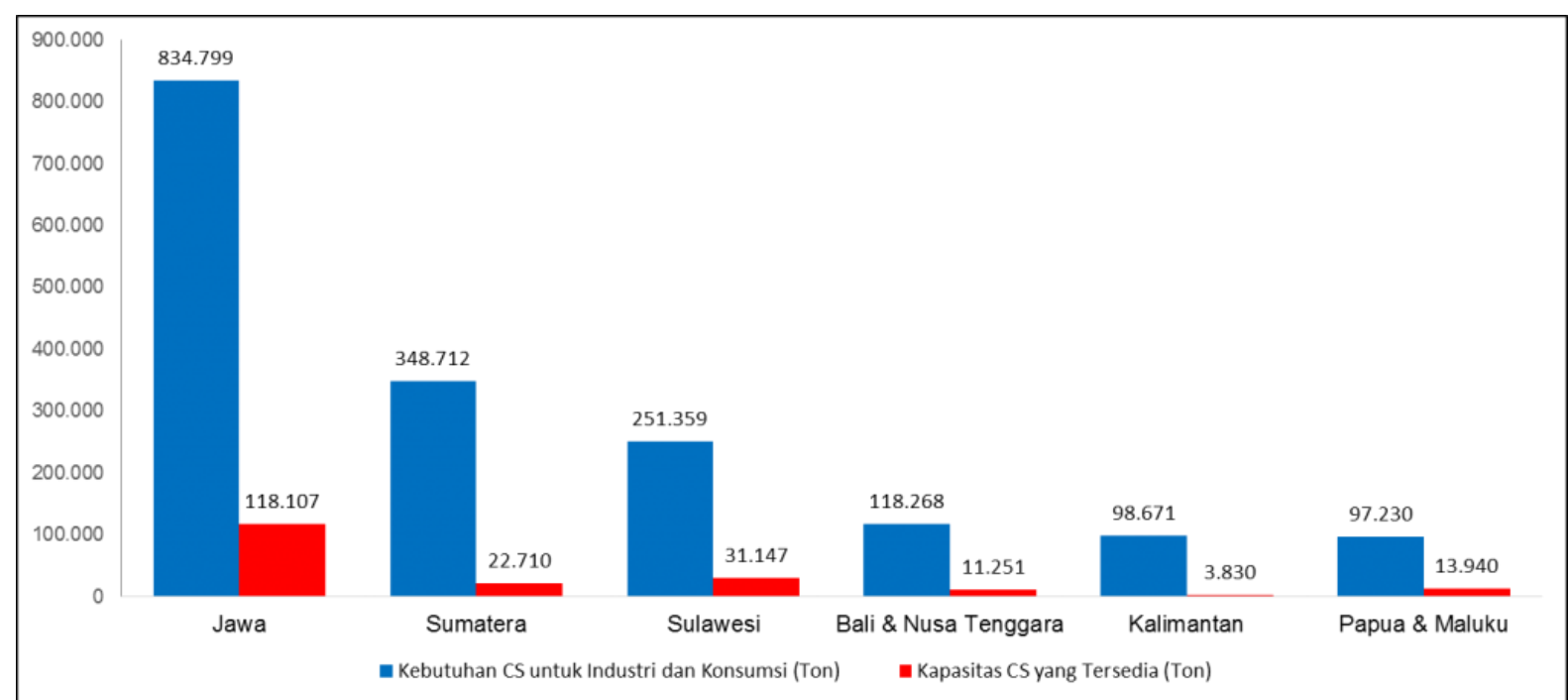

Gambar 1. Grafik Kelautan dan Perikanan

Dalam artikel ini, penulis berfokus pada dua tantangan utama yang dihadapi para pelaku industry cold supply chain di Indonesia. Adapun tantangan ini ditinjau dari aspek teoritis dan aspek yang terjadi di lapangan.

\section{Kajian Pustaka}

Food chain merujuk pada total proses rantai pasok yang berasal dari produksi pertanian, hasil panen atau penyembelihan,melalui produksi primer dan/atau manufaktur, untuk penyimpanandan distribusi, untuk penjualan eceran atau penggunaan dalam catering dan oleh konsumen (Stringer, Hall \& The Breakdowns in Food Society:2007). Menurut Bogataj et al (2007), Cold Chain Management ialah proses perencanaan, pengimplementasian dan pengendalian efisiensi, arus efektif dan penyimpanan barang yang mudah busuk, berkaitan dengan jasa dan informasi dari satu atau lebih titik asal ke titik produksi, distribusi dan konsumsi dalam memenuhi kebutuhan konsumen dalam skala besar.

Alur Cold Chain Supply Management Sumber: Kuo \& Chen (2010:562)

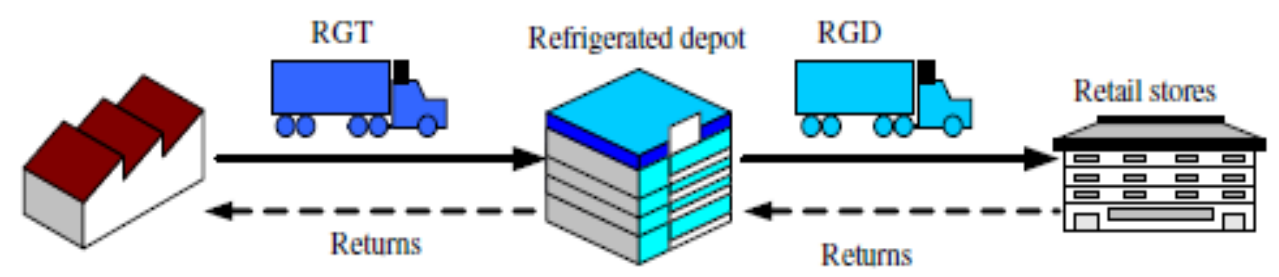

RGT: Refrigerated transportation RGD : Refrigerated distribution 


\section{Metode Penelitian}

Penelitian ini merupakan studi literature dengan mengkaji beberapa entitas yang menjadi factor utama industri cold suplly chain. Adapun hasil kajian tersebut, penulis kaitkan dengan kondisi yang terjadi di Indonesia.

\section{Pengendalian Temperatur dalam Penyimpanan dan Pendistribusian}

Temperatur suhu adalah parameter penting dalam menjaga keamanan dan kualitas produk makanan (Montanari, 2008). Dalam cold supply chain, kondisi temperature mempengaruhi potensi resiko, umur simpan dan kualitas akhir makanan beku (Montanari, 2008). Salah satu atribut dalam sistem logistik untuk makanan beku ialah pemeliharaan kualitas produk yang bergantung pada durasi waktu pengiriman dan variasi temperature dalam cold chain (Zhang, Habenicht \& Spie:2003). Penyimpanan barang makanan segar dalam kondisi dingin atau temperature rendah adalah hal yang esensal karena hal itu dapat meminimalkan resiko makanan dari penyakit, menjaga kualitas optimal dengan mengurangi aktivitas fisiologis dan menghambat pertumbuhan mikroorganisme (Rediers, Claes, Peeters \& Willems:2009).

Adapun dalam menjaga temperatur dingin yang stabil membutuhkan biaya yang sangat besar mulai dari peralatan yang dibutuhkan hingga kedisiplinan operator. Fasilitas penyimpanan harus diatur sedemikian rupa agar tetap dingin meski kondisi di luar fasilitas tersebut berada dalam kondisi yang sangat panas. Di Indonesia dengan iklim tropis dimana cuaca cenderung panas dan lembab menjadikan pengendalian temperature menjadi tantangan yang utama.

Dalam menjaga temperatur tetap dingin membutuhkan peralatan yang memakan daya listrik. Di Indonesia, ketidakstabilan pasokan listrik sering kali menyebabkan gangguan yang berujung pada pemadaman listrik. Hal ini tentu saja berbahaya karena kenaikan suhu yang tiba-tiba justru akan membuat bakan makanan menjadi cepat rusak. Untuk mengatasi hal ini, suatu perusahaan yang bergerak di bidang cold supply chain harus memiliki sumber daya listrik cadangan yang juga memakan biaya yang besar.

Pengendalian temperature juga bergantung pada kualitas sumber daya manusia yang dimiliki perusahaan. Hal ini mengingat bahwa temperature harus dijaga sedemikian rupa dengan pencatatan yang rinci tentang waktu penyimpanan, suhu, dsb. Human error dalam pencatatan pengendalian temperature dapat menyebabkan kerusakan produk.

\section{Kecepatan dalam Pendistribusian Makanan}

Sistem logistic yang efektif tidak hanya harus mengirim produk makanan tetap segar dan aman, tetapi juga harus tepat waktu, yang mana hal ini adalah keinginan konsumen (Kuo \& Chen : 2010). Desain rantai pasok makanan harus mampu mencegah kerugian dalam produksi yang meningkatkan penjualan yang efisien dan mengurangi persediaan dengan meminimalisir waktu siklus pengiriman (Iijima, Komatsu \& Katoh:1996).

Kecepatan dalam pendistribusian makana beku menjadi tantangan yang cukup berat bagi industry cold supply chain di Indonesia, khususnya apabila pendistribusian dilakukan melalui jalur darat. Jalur darat di Indonesia didominasi dengan adanya kemacetan terutama di kota-kota besar. Kemacetan ini menyebabkan semakin 
lamanya penyimpanan makanan beku ketika proses pendistribusian yang berujung cepat rusaknya bahan makanan tersebut.

Dampak dari kemacetan ini berujung pada kerugian materil yakni biaya bahan bakar kendaraan dan kerugian non materil yakni waktu. Selain kemacetan, kondisi infrastruktur di Indonesia yang masih belum merata menjadikan proses pendistribusian bahan makanan ke kota-kota kecil menjadi lebih sulit.

\section{Saran}

Berdasarkan penjabaran tantangan yang dihadapi oleh para pelaku industry cold supply chain penulis menyarankan kepada pemerintah untuk dapat mendukung perkembangan industry ini melalui perbaikan infrastruktur di berbagai wilayah guna kelancaran proses pendistribusian dan penyimpanan makanan beku. Selain itu, pemerintah perlu memberikan insentif bagi pelaku insustri cold supply chain misalnya insentif perpajakan guna menekan biaya yang dikeluarkan mengingat industry cold supply chain memakan biaya yang sangat tinggi.

\section{DAFTAR PUSTAKA}

Bogataj, M., Bogataj, L., \& Vodopivec, R. 2005. Stability of perishable goods in cold logistics chains. International Journal of Production Economics, 93/94(8),345-356.

Iijima, M., Komatsu, S., \& Katoh, S. 1996. Hybrid Just-In-Time Logistics Systems And Information Networks For Effective Management In Perishable Food Industries. International Journal of Production Economics, 44 (1/2), page 97-103

Kuo, Ju Chia \& Chen, Mu Chen. 2010. Developing An Advanced Multi-Temperature Joint Distribution System For Food Cold Chain. Food Control 21 page 559-566

Montanari, R. (2008). Cold chain tracking: A managerial perspective. Trends in Food Science \& Technology, $19(8), 425-431$

Rediers, H., Claes, M., Peeters, L., \& Willems, K. A. 2009. Evaluation of the cold chain of fresh-cut endive from farmer to plate. Postharvest Biology and Technology, 51(2), 257-262.

Stringer, M. F., Hall, M.N., \& The Breakdowns in Food Society Safety Group. 2007. A Generic Model Of The Integrated Food Supply Chain To Aid The Investigation Of Food Safety Breakdowns. Food Control 18 (7) page 755-765

Zhang, G., Habenicht, W., \& Spie, W. E. L. 2003. Improving the Structure of Deep Drozen and Chilled Food Chain with Tabu Search Procedure. Journal of Food Engineering 60 (1) page 67-79. 